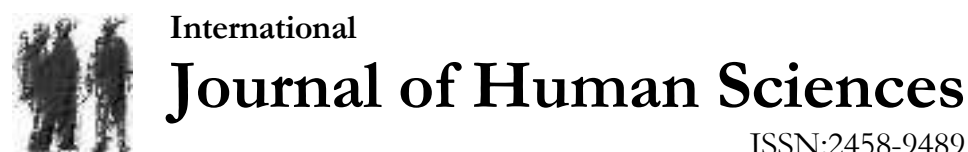

Volume 16 Issue 2 Year: 2019

\section{Human-robot interaction: How do personality traits affect attitudes towards robot?}

\author{
Umit Morsunbul $^{1}$
}

\begin{abstract}
The robot technology seems to be an important part of daily life and has shown great progress in recent years. Robots are used in a lot of parts of life. Thus, we need to think and know how robots will affect human life and how human will react to robots. This study focused on human's attitude toward robots. The first purpose of this study is to determine participants' attitude towards robots and second is to investigate how personality traits predict their attitudes towards robots. Participants consisted of 219 (142 female and 77 male) university students. Of the participants were university students and their age was between 18-26 years old (mean age $=20.54, \mathrm{SD}=1.22$ ). Negative Attitude towards Robot Scale and Quick Big Five Personality Test were used to collect data. Results indicated that gender, extraversion and openness to experience are important factors for participants' attitude towards robots. Considering speed technological development we need more researches to evaluate correctly human-robot interactions.
\end{abstract}

Keywords: Robot, attitude, personality, gender.

\section{Introduction}

Technology has become basic part of daily life in many areas. Especially, robot technology seems to be important part of daily life and has shown great progress in recent years. Robots are used in a lot of parts of human's life. The robot Ramboo is used for cleaning, the entertainment robot Pleo, the therapy robot Paro is used for people suffering from dementia and trauma, the female sex robot Roxxxy and the male sex robot Rambo designed as sexual partners (Morsünbül, 2018; Sullins 2012, Richards, Cross \& Quinn, 2017). Specifically, computer scientists, engineers or roboticists are interested in creating and developing robots (Kuhnert, Ragni \& Linder, 2017). According to David Levy, human-robot connection will be normal by 2050 and may be more than human-to-human connection (Richards, Coss \& Quinn, 2017; Sullins 2012). Levy's argument does not seem exaggerated considering the rapid development of smart phones and the place of them in our lives (Morsünbül, 2018). Thus, we need to think and know how robots will affect human life and how human will react to robots. Mutlu, Osman, Forlizzi, Hodgins, \& Kiesler (2006) defined three factors that may affect human-robot interactions: Robot attributes (e.g. appearance and character), user's personal factors (age, gender, personality) and the nature of the task being performed (e.g. collaborative and competitive tasks).

${ }^{1}$ Assoc. Prof. Dr., Aksaray University, Educatin Faculty, morsunbulumit@gmail.com 
This study focused on personality traits to investigate attitudes towards robots. Different approaches (such as psychoanalytic, behaviorist, trait approach) have been used to investigate personality. In recent years Big-Five Personality Theory has been used frequently in order to measure and assess personality (Santamaria \&Roberts, 2017). Compared with other traits extraverts have higher social skills, outgoing and energetic scores. Agreeable people have higher friendship, sympathy, respectfulness, and compassionate scores. People high in emotional stability have higher secure, calmness and confident scores. People in high conscientiousness have higher self-discipline, efficiency and organization scores. People high in openness to experience have higher inventiveness, curiosity, and openness to new ideas scores (Mc Aams \& Olson, 2010; Morsünbül, 2014).

According to European Commission Report (2012) 60\% of the participants reported that robots shouldn't be used for the care of children, elderly people and people with disabilities. $34 \%$ of participants reported that robots shouldn't be used in education areas. $27 \%$ participants reported that robots shouldn't be used in healthcare and finally $20 \%$ of the participants are opposed to using robots in leisure purposes. Studies about attitudes towards robots in Turkey are very limited. Thus, we need studies that examine which factors affect human's attitude towards robots. As a result, the study has two main purposes. The first purpose of this study is to determine participants' opinion towards robots and second is to investigate how personality traits predict their negative attitudes towards robots.

\section{Method}

\section{Participants}

Participants consisted of 219 (142 female and 77 male) university students. Of the participants were university students and their age was between 18-26 years old (mean age $=20.54$, $\mathrm{SD}=1.22$ ). The data was collected between 19 April and 17 May 2018.

\section{Measures}

Demographics. In order to obtain information on demographic features of the participants personal data form was used. Also, a questionnaire was developed to determine the participants' opinions about robots.

Attitudes towards robot. Negative Attitude Towards Robot Scale (NARS) was used in order to measure participants' attitude towards robots. The scale was developed by Nomura, Kanda and Suzuki (2006) and adapted to Turkish within scope of this study. This scale consists of 14 items including negative attitude towards situations of interaction with robots, negative attitude towards social influence of robots and negative attitude towards emotions in interaction with robots domains and these three domains were combined for obtaining overall attitude scores. Each item is rated on a 5-point Likert scale that ranges from 1 (strongly disagree) to 5 (strongly agree).

Initially NARS was translated into Turkish from English by three academicians and then common points were sought by bringing together all translations. Different expressions were made into common expressions. Turkish form created on the basis of expert opinion was again translated into English by different academicians. Confirmatory factor analysis confirmed that Turkish form of NARS has three factors. The indices of goodness of fit in this factor analysis were as follows: $\mathrm{GFI}=0.90, \mathrm{NFI}=0.92, \mathrm{RMSEA}=0.08$. Cronbach `s alphas were .85 for total negative attitude, .82 for negative attitude towards situations of interaction with robots, .63 for negative attitude towards social influence of robots and .70 for negative attitude towards emotions in interaction with robots. 
Morsünbül, Ü. (2019). Human-robot interaction: How do personality traits affect attitudes towards robot?. Journal of Human Sciences, 16(2), 499-504. doi: 10.14687/jhs.v16i2.5636

Personality. Personality traits were measured by Quick Big Five Personality Test (QBFT). The test developed by Verlmuts and Gerits (2005) and adapted to Turkish by Morsünbül (2014). QBFT consists of 30 items. Cronbach`s alphas were .84 for extraversion, .85 for conscientiousness, for agreeableness .66, for openness to experience .65 and .70 for emotional stability.

\section{Procedure}

The purpose of study explained to participants before data collection. Participants answered the questions on average within 45 minutes.

\section{Data Analysis}

Descriptive statistics were conducted to analyze demographic variables. Correlation analysis in order to determine relations between the variables and finally, regression analysis was conducted to investigate how personality traits predict human's attitude towards robots.

\section{Results}

\section{Participants' Opinions about Robots}

As reported in Table 1 most of the participants watched movies and series and they would like to have humanoid robot. Most of the participants reported positive opinion about using of robots in the care of elderly, disabled and sick people but most of them were against using robot in the care of babies and children. Most of the participants stated that a romantic relationship with a robot is not possible but nearly half of the participants reported that they can have emotional intimacy with robots. Most of the participants stated that sexual relationship of a married woman/man with robot is cheating.

Table 1

Participants' opinions about robots

\begin{tabular}{|c|c|c|}
\hline & $\begin{array}{l}\text { Yes } \\
\%\end{array}$ & $\begin{array}{l}\text { No } \\
\%\end{array}$ \\
\hline 1. Did you watch any movies or series about robots? & 85.8 & 14.2 \\
\hline 2. Would you like to have humanoid robot? & 71.7 & 28.3 \\
\hline 3. Should robots be used in the care of elderly, disabled and sick people? & 76.3 & 23.7 \\
\hline 4. Should robots be used in the care of babies and children? & 32.4 & 67.6 \\
\hline 5. Is it possible for people to have romantic relationships with robots? & 39.7 & 60.3 \\
\hline 6. People may have sex with robots. & 37.4 & 62.6 \\
\hline $\begin{array}{l}\text { 7. People who fail to establish intimacy with people may have sex with } \\
\text { robots }\end{array}$ & 45.2 & 54.8 \\
\hline $\begin{array}{l}\text { 8. Is this cheating a married woman to have sexual relationships with male } \\
\text { robot? }\end{array}$ & 75.3 & 24.7 \\
\hline $\begin{array}{l}\text { 9. Is this cheating a married man to have sexual relationships with female } \\
\text { robot? }\end{array}$ & 74.4 & 25.6 \\
\hline $\begin{array}{l}\text { 10. Do you think individuals who have sex with robots experience a } \\
\text { mental disorder? }\end{array}$ & 76.3 & 23.7 \\
\hline $\begin{array}{l}\text { 11. Should laws be taken to protect the rights of robots if robots begin to } \\
\text { take a big place in human life in the future? }\end{array}$ & 60.3 & 39.7 \\
\hline 12. I can have emotional intimacy with robot. & 46.1 & 53.9 \\
\hline
\end{tabular}


Morsünbül, Ü. (2019). Human-robot interaction: How do personality traits affect attitudes towards robot?. Journal of Human Sciences, 16(2), 499-504. doi: 10.14687/jhs.v16i2.5636

\section{Correlation between personality traits and negative attitudes towards robots}

Table 2 presents means and standard deviations of personality traits and their correlation with negative attitudes towards robots. As can be seen agreeableness $(\mathrm{r}=-.16, \mathrm{p}<.05)$, extraversion $(\mathrm{r}=-.15, \mathrm{p}<.05)$ and openness to experience $(\mathrm{r}=-.26, \mathrm{p}<.01)$ were negatively related to negative attitudes towards robots.

Table 2

Means and standard deviations of variables and their correlation with negative attitudes towards robots

\begin{tabular}{lrcc}
\hline Variable & Mean & \multicolumn{1}{l}{ Sd } & Negative attitudes towards robots \\
\hline Agreeableness & 5.45 & .71 & $-.16^{*}$ \\
Extraversion & 4.24 & 1.16 & $-.15^{*}$ \\
Conscientiousness & 4.61 & 1.21 & .03 \\
Openness to experience & 5.02 & .74 & $-.26^{* *}$ \\
Emotional stability. & 3.94 & .96 & .04 \\
Negative attitudes towards robots & 2.52 & .56 & 1 \\
\hline
\end{tabular}

$* \mathrm{p}<.05, * * \mathrm{p}<.01$

\section{Regression Analysis Results}

Regression analysis was conducted in order to how well negative attitudes towards robots are predicted by gender and personality traits. As can be seen in Table 3 independent variables significantly predicted smoking status $\left(\mathrm{R}=.40 \mathrm{R}^{2}=.16 \mathrm{~F}=6.75^{* *} \mathrm{p}<.01\right)$. This finding presents that independent variables accounted for $16 \%$ variance of negative attitudes towards robots. According to regression analysis results gender $(\beta=.22, \mathrm{p}<.01)$, extraversion $(\beta=-.14, \mathrm{p}<.05)$, and openness to experience $(\beta=-.24, \mathrm{p}<.01)$ significantly predicted negative attitudes towards robots.

Table 3

Regression analysis results

\begin{tabular}{lllllll}
\hline Variables & B & Sd & B & T & Tolerance & VIF \\
\hline Gender & 3.73 & 1.05 & .22 & $3.52^{* *}$ & .96 & 1.03 \\
Agreeableness & -.16 & .12 & -.09 & -1.32 & .84 & 1.18 \\
Extraversion & -.16 & .07 & -.14 & $-2.16^{*}$ & .91 & 1.08 \\
Conscientiousness & .07 & .07 & .07 & 1.07 & .88 & 1.12 \\
Openness to experience & -.43 & .12 & -.24 & $-3.55^{* *}$ & .84 & 1.18 \\
Emotional stability. & .16 & .09 & .11 & 1.78 & .92 & 1.08 \\
\hline
\end{tabular}

$. \mathrm{R}=.40 \mathrm{R}^{2}=.16 \quad \mathrm{~F}=6.75 \quad * * \mathrm{p}<.01$

Gender: $1=$ Female, $0=$ Male

$* \mathrm{p}<.05,{ }^{* *} \mathrm{p}<.01$

\section{Discussion}

Autonomous robots will be part of life and humans will have to interact with them in domestic environments in the future (Rossi, Dautenhahn, Koay \& Walters, 2018). According to Levy (2007) people will use robots to eliminate their loneliness with robots and also human-robot marriages will be very normal in the next 30 years. Therefore, we need to have more information about human-robot interaction and human's attitudes towards robots. This study aimed to contribute to human's attitudes towards robots.

Results indicated that most of the participants have watched movies and series related to human-robot interactions. Recent years a lot of movies and series (Ex Machine (2015), Humans (2015), Westworld (2016)) have been released. Producers have spent huge budgets for these movies and series because of their high ratings. According to results, most of the participants would like to have humanoid robot and nearly half of them reported that they can have emotional intimacy with 
Morsünbül, Ü. (2019). Human-robot interaction: How do personality traits affect attitudes towards robot?. Journal of Human Sciences, 16(2), 499-504. doi: 10.14687/jhs.v16i2.5636

robot. These results indicated that participants have positive opinions about robot and humanoid robot.

According to results, participants have positive opinions about using robots in the care of elderly, disabled and sick people but not in the care of babies and children. These results can be interpreted as participants think that humans should care of babies and children.

Results showed that most of the participants think that sexual relationship of a married woman/man with robot is cheating. These results may be interpreted as participants see robots like human. In other words, they attribute human characteristics to robot. In the study that conducted by Huffington Post and YouGov. $42 \%$ of participants answered yes while $31 \%$ of participants answered no about similar question on cheating. The rest of the respondents reported that they were indecisive. There is no compromise about sex with robot. Some people think that sex with robot is like masturbation rather than sex between people and it cannot be evaluated as cheating (Scheutz \& Arnold, 2016). As a result, sex with robot will be often discussed both legally and morally in the future (Cheok, Karunanayaka, \& Zhang, 2017; Morsünbül, 2018; Scheutz \& Arnold 2016).

Results indicated that gender is a significant factor for negative attitudes towards robots. Females reported more negative attitudes towards robot than males. This result consisted with results of previous studies (Kuo et al., 2009; Wang \& Young, 2014). According to Mutlu et al. (2006) men's perception of and interaction experience with the robot mostly depended on the task structure. Also, men have greater desirability towards robot in cooperative tasks which suggests better acceptance (Kuo et al., 2009). This difference may be related to designers of the robots. Men are much more likely to be technology designers and they may consider much more men's characteristics (Wang \& Young, 2014). We can see this situation particularly in design of sex robots that their producers are specifically interested in men consumer. According to Wang and Young (2014) women and men look at life from different perspectives. Therefore, women evaluate robots according to effects of them on changing their personal everyday life while men evaluate robots according to their potential effects on their jobs and social status.

In terms of personality traits, extraversion and openness to experience negatively predicted participants' negative attitudes towards robots. In other words, people with high extraversion or openness to experience have more positive attitudes towards robots. These results consisted with results of previous studies (Conti, Commodari \& Buono, 2017; Santamaria \& Roberts, 2017). People with high openness to experience enjoy trying new things. They seek out new, unconventional and unfamiliar experiences and they are more open to technological development or experiences with robots. People with high extraversion also reported more positive attitudes towards robots. Humanoid robots may be attracting their attention because they enjoy being with people. The design of human-robot-interaction could be an adaptive communication behavior to the needs of extraverted people by focusing on social interaction skills (Müller \& Richert, 2018).

\section{Conclusion}

As a result this study indicated that gender and some personality traits are crucial factors for attitudes towards robots. Considering speed technological development we need more researches to evaluate human-robot interactions from different points. We will need to both legal and moral rules about human-robot connections and also need to programs that help people to adapt humanrobot connection. Finally, mental health experts should investigate human-robot interaction from mental health perspective and try to describe what healthy behaviors are in human-robot interaction. 
Morsünbül, Ü. (2019). Human-robot interaction: How do personality traits affect attitudes towards robot?. Journal of Human Sciences, 16(2), 499-504. doi: 10.14687/jhs.v16i2.5636

\section{References}

Cheok, A. D., Karunanayaka, K., \& Zhang, E. Y. (2017). Human-robot love and sex relationships. In Robot Ethics: From Autonomous Cars to Artificial Intelligence, (Eds P Lin, K Abney, R Jenkins): 193-220. Oxford University Press.

European Commission. (2012). Eurobarometer Special 382: Public Attitudes towards Robots. Brussels, Belgium.

Kunhert, B., Ragni, M., \& Linder, F. (2017, August). The gap between buman's attitude towards robots in general and human's expectation of an ideal everyday life robot. Paper presented 26th IEEE International Symposium on Robot and Human Interactive Communication (RO-MAN), Lisbon, Portugal.

Kuo, I. H., Rabindran, J. M., Broadbent, E., Lee, Y. I., Kerse, N., Stafford, R. M. Q., et al. (2009, September). Age and gender factors in user acceptance of healthcare robots. Paper presented 18th IEEE International Symposium on Robot and Human Interactive Communication. Toyama, Japan.

Levy, D. (2007). Love and sex with robots: The evolution of human-robot relationships. Harper Collins.

McAdams, D.P., \& Olson, B.D. (2010). Personality development: Continuity and change over the life course. Annual Revien Psychology, 61:517-542.

Morsünbül, Ü. (2014). The validity and reliability study of the Turkish version of Quick Big Five Personality Test. The Journal of Psychiatry and Neurological Sciences, 27, 316-322.

Morsünbül, Ü. (2018). Attachment and sex with robot: An assessment from mental health perspective. Current Approaches in Psychiatry, 10, 417-429.

Mutlu, B., Osman, S., Forlizzi, J., Hodgins, J., \& Kiesler, S. (2006, September). Task Structure and User Attributes as Elements of Human-Robot Interaction Design. Paper presented 15 th IEEE International Symposium on Robot and Human Interactive Communication. Hatfield, UK.

Müller, S. L. \& Richert, A. (2018). The Big-Five Personality Dimensions and Attitudes Towards Robots: A Cross Sectional Study. Paper presented 18 th The Pervasive Technologies Related to Assistive Environments Conference. Corfu, Greece.

Nomura, T., Kanda, T., \& Suzuki, T. (2006). Experimental investigation into influence of negative attitudes toward robots on human-robot interaction. AI \& Society. 20, 138-150.

Richards, R., Coss, C., \& Quinn, J. (2017). Exploration of relational factors and the likelihood of a sexual robotic experience. In Love and Sex with Robots, (Eds AD Cheok, K Devlin, D Levy): 97-103. London, Springer.

Rossi, A., Dautenhahn, K., Koay, K. L., \& Walters, M. (2018). The impact of peoples' personal dispositions and personalities on their trust of robots in an emergency scenario. Paladyn, Journal of Behavioral Robotics, 9, 137-154.

Santamaria, T., \& Roberts, D. N. (2017, October). Personality Measurement and Design in Human-Robot Interaction: A Systematic and Critical Review. Paper presented Human Factors and Ergonomics Society 2017 Annual Meeting, Austin, USA.

Scheutz, M., \& Arnold, T. (2016, March). Are we ready for sex robots?. Paper presented Eleventh ACM/IEEE International Conference on Human Robot Interactions. Christchurch, New Zealand.

Sullins, J. P. (2012). Robots, love and sex: The ethics of building a love machine. IEEE Transactions On Affective Computing, 3, 398-409.

Vermulst, A. A., \& Gerris, J. R. M. (2005). QBF: Quick Big Five persoonlijkheidstest handleiding [Quick Big Five personality test manual]. Leeuwarden, the Netherlands: LDC Publications.

Wang, Y. \& Young, J. E. (2014). Beyond "pink" and "blue": Gendered attitudes towards robots in society. Proceedings of Gender and IT Appropriation (GenderIT'14), Pages 49 -59. 